\title{
ATTRACTION OF CULICOIDES FURENS AND C. HOLLENSIS (DIPTERA: CERATOPOGONIDAE) TO ANIMAL HOSTS IN A SALT MARSH HABITAT ${ }^{1}$
}

\author{
By H. G. Koch ${ }^{2,3}$ and R. C. Axtell ${ }^{2}$
}

Abstract: Host attraction studies of adult Culicoides furens and C. hollensis were conducted in a Spartina salt marsh in Carteret County, North Carolina, USA. The attractancy of domestic animals (Japanese Quail, white rat, White Leghorn chicken and New Zealand white rabbit) was decermined using animalbaited traps in a Latin square experimental design. Paired comparisons of domestic animals with wild live-trapped animals from the marsh (Hispid Cotton Rat, Mallard Duck, Virginia Opossum, Raccoon and Marsh Rice Rat) were made using the same type of traps. In general, the degree of attractiveness of the animals to $C$. furens and $C$. hollensis was related more to the size of the amimal than to the kind of animal. There were little differences in the attractancy of domestic and wild animals. It was concluded that $C$. furens and $C$. hollensis have a wide host range and should not be classified as either ornithophilic or mammalophilic. Catches of Culicoides by animal-baited traps were poorly correlated with catches in nearby emergence and sticky cylinder traps.

Culicoides furens (Poey) and C. hollensis (Melander $\&$ Brues) are the 2 most abundant salt marsh biting midges (Ceratopogonidae) of coastal North Carolina (Kline \& Axtell 1976, 1977), as well as many other coastal areas of eastern North America. The literature on Ceratopogonidae has recently been reviewed by Linley (1976) and Kettle (1977). Little information is available on the host range or preference of salt marsh Culicoides.

Many species of Culicoides have been classified as ornithophilic or mammalophilic, based on collections from caged animals, baited traps or observations (Bennett 1960, Fallis 1958, Fallis \& Wood 1957, Hair \& Turner 1968, Jones 1959). Jamnback (1965) and Battle \& Turner (1971) listed the host records of most Culicoides species in the eastern United States. The number of olfactory pits on the antennae of female Culicodes has been correlated with host preference, and ornithophilic species have been claimed to have more olfactory pits than

\footnotetext{
${ }^{1}$ This research was supported by NOAA, Office of Sea Grant, U.S. Department of Commerce, under Grant No. 04-3-158-40 and the North Carolina Department of Administration. Paper No. 5477 of the Journal Series of the North Carolina Agricultural Experiment Station.

${ }^{2}$ Department of Entomology, North Carolina State University, Raleigh, North Carolina 27607, USA.

${ }^{3}$ Present address: Lone Star Tick Laboratory, USDA, ARS, P. O. Box 588, Poteau, Oklahoma 74953, USA.
}

those species feeding on mammals (including man) (Jamnback 1965).

As pointed out by Gillies (1972), host choice is mainly determined by ecological factors and host availability and the only practical approach to the study of host choice is to compare the responses of different insect species to several different alternate hosts. Large populations and adequate seasonal abundance information on $C$. furens and $C$. hollensis facilitated our investigation on host attraction under field conditions.

\section{MATERIALS AND METHODS}

Study site

The experiments were conducted during the spring and summer (March-August) of 1975 and 1976 in a salt marsh along the Newport River at the end of Lake Shore Drive, Morehead City, North Carolina. The dominant plant cover was Spartina alterniflora Loiseleur which occurred in the tall form $(>1.2 \mathrm{~m}$ height), intermediate form $(0.3-1.2 \mathrm{~m})$, and short form $(<0.3 \mathrm{~m})$ with smaller zones of Distichlis spicata (L.) Greene and Juncus roemerianus Scheele. Most of the marsh was regularly flooded and contained both natural and manmade ditches. A narrow band of high marsh shrubs separated the marsh from a forest of hardwoods on the upland. The study area is the same as shown in Fig. 2 of Dukes et al. (1974) and described in Kline \& Axtell (1977).

A portion of the marsh $(100 \mathrm{~m} \times 100 \mathrm{~m})$ consisting of nearly pure strands of short-form $S$. alterniflora and intermediate form S. alterniflora was used for the experiments. The center of this area was located $240-250 \mathrm{~m}$ southward from the river's edge and 100-110 $\mathrm{m}$ northward from the hardwood forest. A $120-150 \mathrm{~m}$ zone of tall-form $S$. alterniflora bordered the river. A man-made ditch (15-18 m wide) with a 10-12 $\mathrm{m}$ band of tall-form $S$. alterniflora ran parallel with and $120-130 \mathrm{~m}$ from the western edge of the site. Two natural drainage ditches with 1-2 m bands of tall-form $S$. 
alterniflora were in the adjacent marsh to the north and east. Two large D. spicata patches (900-1000 $\mathrm{m}^{2}$ each) were $210-270 \mathrm{~m}$ northeast of the center of the site. A large area of marsh (8000-9000 $\left.\mathrm{m}^{2}\right)$ dominated by $J$. roemerianus was $240-360 \mathrm{~m}$ southeast of the center of the site.

\section{Trap descriptions and arrangements}

Animal-baited traps similar to those described by Turner (1972) were used to determine the relative attractiveness of various domestic and wild hosts to $C$. furens and $C$. hollensis. The traps consisted of elongate wooden frames $(38 \times 36 \times 53$ $\mathrm{cm})$ with plywood bottoms $(38 \times 53 \mathrm{~cm})$. The 4 sides of the traps were covered with Saran ${ }^{\circledR}$ screen (44 mesh) with 2.5-cm-long vertical slits cut into the fabric. The upper $1 / 3$ of each trap was covered with opaque black plastic and a translucent collector funnel assembly mounted on the top at 1 end. Wire animal cages $(30 \times 30 \times 57 \mathrm{~cm})$ containing the bait animals were inserted into the trap from 1 end and the screen secured with thumbtacks. Adult Culicoides entered the traps through the vertical slits and were attracted to the collector funnels by the light coming through the semitransparent material. Once trapped inside the funnel assembly, they eventually fell into collecting jars containing $75 \%$ ethanol.

Sticky cylinder traps and emergence traps as described by Kline \& Axtell (1976) were used to determine the activity and abundance of Culicoides in the study area. Each sticky cylinder trap was a section of black plastic sewer pipe attached to a blackpainted wooden post so that the center was $1.8 \mathrm{~m}$ above the ground. A sheet of cellulose acetate, thinly coated with Bird Tanglefoot ${ }^{\circledR}$, was wrapped around the cylinder and held with metal clips. An emergence trap was a metal cone surmounted by a glass jar containing a cellulose acetate sleeve coated with Bird Tanglefoot ${ }^{\circledR}$. Adult gnats were captured on the sticky surfaces of the cellulose acetate and removed for identification by rinsing the strips in refined kerosene $\left(\operatorname{Varsol}^{\circledR}\right)$.

The trap arrangement on the marsh is shown in FIG. 1. Sixteen identical animal-baited traps were spaced $25 \mathrm{~m}$ apart in 4 rows and columns forming a square. The traps were elevated $1 \mathrm{~m}$ above the marsh surface by tying them atop panel traps (without the adhesive). Each panel trap, as illustrated and described by Dale \& Axtell (1976), consisted of 4 black masonite $0.3 \mathrm{~m} \times 0.3 \mathrm{~m}$ panels mounted on a red-painted wood pole. The animal-

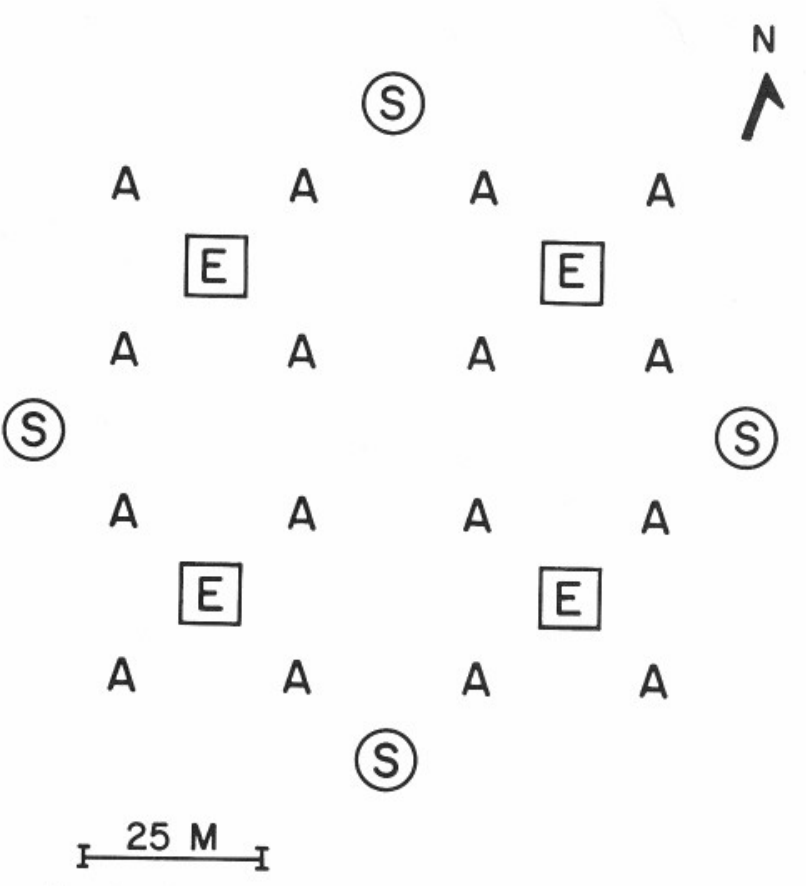

FIG. 1. Arrangement of animal-baited traps (A), emergence traps (E), and sticky cylinder traps (S) in a Spartina salt marsh.

baited traps were oriented with the collector funnels facing north. One of the 4 emergence traps was placed $17 \mathrm{~m}$ toward the center of the square from each corner animal-baited trap. One of the 4 sticky cylinder traps was placed $17 \mathrm{~m}$ outside the middle of each side of the square. In the paired comparisons experiments, the 2 animal-baited traps were placed in adjacent columns in the same row.

\section{Test animals and experimental procedures}

Four domestic species ( 1 small and 1 intermediate-sized bird and mammal) were chosen as standard host animals and their attractancy to Culicoides compared using a $4 \times 4$ randomized Latin square design. Caged Japanese Quail $(0.2-0.3 \mathrm{~kg})$, laboratory white rat $(0.3-0.5 \mathrm{~kg})$, White Leghorn chicken $(2.5-3.5 \mathrm{~kg})$, and New Zealand white rabbit $(2.7-3.5 \mathrm{~kg})$ were randomly distributed among the animal-baited traps in each row and column (16 animals). The jars of alcohol containing the insects were changed in the early morning when Culicoides activity was very low and after $24 \mathrm{~h}$ of host exposure. The animal-baited traps were then cleaned and relocated to form a new randomized Latin square. Collections from the emergence and sticky cylinder traps were also recovered during 


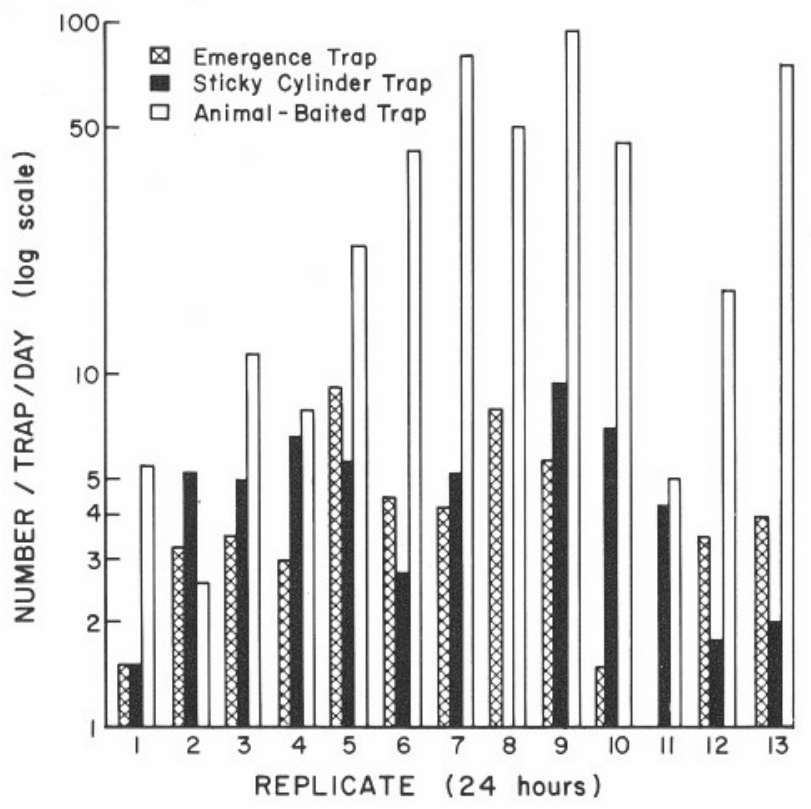

Fig. 2. Comparison of mean number (log scale) of adult Culicoides furens captured/trap/day by animal-baited traps (16 traps with 4 different hosts), sticky cylinder traps (4) and emergence traps (4) in a Spartina salt marsh during thirteen 24-h trapping periods (replicates).

the 24-h period of host exposure. There were 13 replicates (24-h periods) for C. furens in the summer of 1975 and 12 for C. hollensis in the spring of 1976. It was previously determined (Kline \& Axtell 1976) at the study site that C. furens was most abundant in the summer and $C$. hollensis in the spring.

Paired comparisons were made of standard domestic host animals with the following wild animals native to the study area: Hispid Cotton Rat (Sig-

TABLE 1. Mean no. of Culicoides furens and $C$. hollensis caught in animal-baited traps containing 4 domestic hosts in a Spartina salt marsh.*

\begin{tabular}{|c|c|c|c|}
\hline \multirow[b]{2}{*}{ BAIT ANIMAL } & \multirow{2}{*}{$\begin{array}{c}\text { MEAN } \\
\text { HOST } \\
\text { WEIGHT } \\
(\mathrm{kg})\end{array}$} & \multicolumn{2}{|c|}{ MEAN NO./TRAP/DAY } \\
\hline & & $\begin{array}{c}C . \\
\text { furens }\end{array}$ & $\begin{array}{c}C . \\
\text { hollensis }\end{array}$ \\
\hline White Leghorn chicken & 3.11 & $74.23 \mathrm{a}$ & $37.52 \mathrm{a}$ \\
\hline New Zealand white rabbit & 3.12 & $38.46 \mathrm{~b}$ & $26.16 \mathrm{~b}$ \\
\hline White rat & 0.48 & $22.50 \mathrm{c}$ & $17.67 \mathrm{bc}$ \\
\hline Japanese Quail & 0.21 & $10.50 \mathrm{c}$ & $6.46 \mathrm{c}$ \\
\hline
\end{tabular}

* Sixteen animal-baited traps with equal numbers of the 4 hosts were arranged in a $4 \times 4$ randomized Latin square design and replicated 13 days for C. furens in 1975 and 12 days for C. hollensis in 1976.

** Within each column means followed by the same letters are not significantly different at the $5 \%$ level of probability (LSD comparisons).

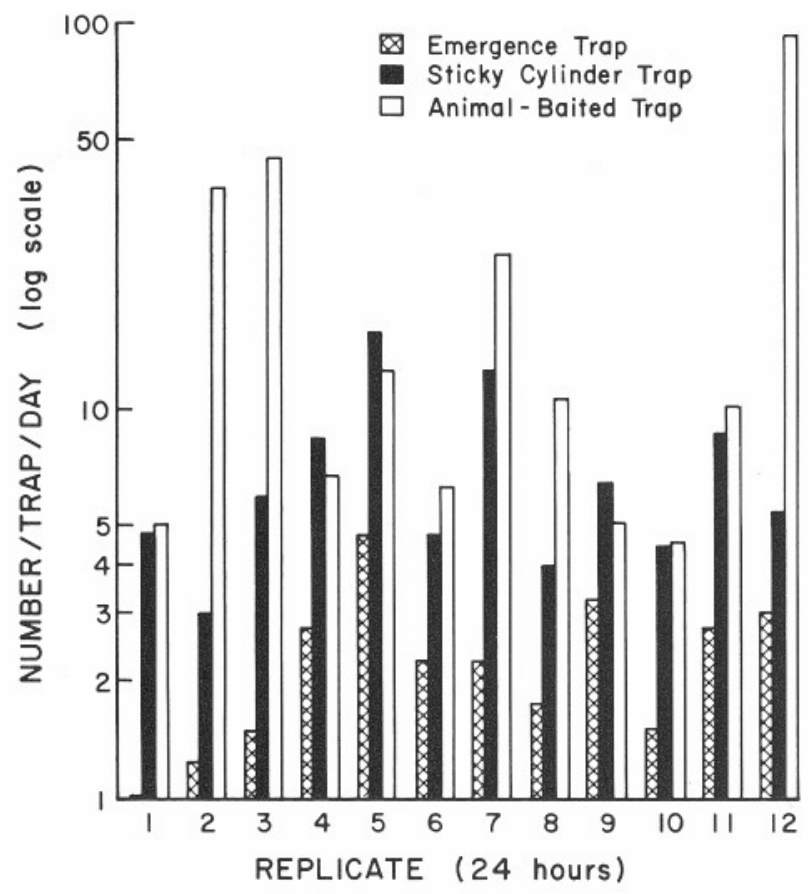

FIG. 3. Comparison of mean number (log scale) of adult Culicoides hollensis captured/trap/day by animal-baited traps (16 traps with 4 different hosts), sticky cylinder traps (4) and emergence traps (4) in a Spartina salt marsh during twelve 24-h trapping periods (replicates).

modon hispidus), Mallard Duck (Anas platyrhynchos), Virginia Opossum (Didelphis virginiana), Raccoon (Procyon lotor) and Marsh Rice Rat (Oryzomys palustris). The wild animal species (1-3 specimens each) were live-trapped (Havahart ${ }^{\circledR}$ traps) near the study area, weighed, and placed individually into animalbaited traps opposite other traps containing standard hosts. Comparisons were made between host species most closely related in phylogeny and weight. The positions of the animal-baited traps were reversed following each of 3 successive $24-\mathrm{h}$ host exposure periods (from morning to early next morning).

Unbaited traps were not used as controls, since preliminary studies in 1974 showed that no Culicoides were caught in unbaited traps, while traps containing dry ice and small animals captured large numbers. In addition, several uncleaned traps were left on the marsh in 1976 following the animal bait studies and checked daily for 2 weeks, and no Culicoides were trapped.

\section{RESULTS}

The mean number of $C$. furens and $C$. hollensis caught in animal-baited traps containing weighed 
TABLE 2. Mean no. of Culicoides furens and C. hollensis caught in animal-baited traps in paired comparisons of standard domestic host animals vs live-trapped wild animals in a Spartina salt marsh.

\begin{tabular}{lllr} 
& & \multicolumn{2}{c}{ MEAN NO. GNATS/TRAP/DAY* } \\
\cline { 3 - 4 } DOMESTIC & WILD & Domestic & Wild
\end{tabular}

C. furens (1975)

Chicken $(1.73)^{* *}$

Chicken (1.54)

Rabbit (3.18)

Rabbit (3.64)

White rat $(0.45)$

White rat $(0.45)$

C. hollensis (1976)

White rat $(0.51)$

White rat $(0.34)$

White rat $(0.68)$

Rabbit (3.75)

Rabbit (3.75) vs Mallard Duck (1.08)

vs Mallard Duck (1.02)

vs Raccoon (5.45)

vs Raccoon (5.91)

vs Marsh Rice Rat (0.11)

vs Hispid Cotton Rat (0.09)

vs Hispid Cotton Rat (0.23)

vs Hispid Cotton Rat $(0.57)$

vs Marsh Rice Rat (0.28)

vs Virginia Opossum (2.27)

vs Raccoon (4.55)
31.33

6.00

8.33

$68.66 * * *$

$77.33 * * *$

3.00

\subsection{0}

3.00

1.66

6.66

$12.33 * * *$

* Mean of three 24-h exposure periods per comparison.

** Number in parentheses is host weight $(\mathrm{kg})$. level).

*** Differences significant at the $5 \%$ level of probability ( $t$-test); differences between other comparisons not significant ( $5 \%$

standard domestic hosts is given in TABLE 1. For both species, the greatest numbers were captured in the chicken-baited trap, followed in descending order by rabbit-, rat-, and quail-baited traps. Only female Culicoides were trapped. There were no significant $(P<0.05)$ differences in the number of Culicoides caught by animal-baited traps in different rows and columns except that the number of $C$. furens captured in the row nearest to the woods (ca $65 \mathrm{~m}$ ) was significantly higher than the others. The position of emergence and the sticky cylinder traps did not significantly influence numbers of Culicoides captured.

FIG. 2 and 3 show the mean number per trap of C. furens and C. hollensis, respectively, captured during each 24-h period by the animal-baited traps, sticky cylinder traps, and emergence traps. A large variation between successive replications was evident and the correlation among trap catches within replicates was often low. For example, replicate 8 for $C$. furens shows no catch with sticky cylinder traps but shows the 2nd highest emergence trap catch and the 4th highest animal-baited trap catch. The overall mean number of adults collected per trap per day was greatest from animalbaited traps (36.4 C. furens and 21.9 C. hollensis) but significantly less from sticky cylinder traps (4.3 C. furens and 7.0 C. hollensis) and emergence traps (4.0 C. furens and 2.3 C. hollensis).

The numbers of $C$. furens and $C$. hollensis taken in paired comparisons of standard host animals and live-trapped animals are shown in TABLE 2 . Two comparisons for $C$. furens (rabbit vs Raccoon and white rat vs rice rat) and 1 for C. hollensis (rabbit vs Raccoon) showed significant differences in the number of insects captured. Other comparisons involving Mallard Duck, cotton rat, and opossum were not significant $(P>0.05)$, but low numbers of Culicoides were captured during the testing periods, making it difficult to interpret some results. Generally, more Culicoides were captured in the traps with the heavier animals, but it was not a simple linear relationship. For example, with a 5.91-kg Raccoon, 68.86 C. furens/trap/day were caught vs 6.66 with a $3.64-\mathrm{kg}$ rabbit and $12.33 \mathrm{C}$. hollensis with a 4.55 - $\mathrm{kg}$ Raccoon vs 8.33 with a 3.75 $\mathrm{kg}$ rabbit. Also, with a $0.45-\mathrm{kg}$ white rat, $204.33 \mathrm{C}$. furens were caught vs 77.33 with a $0.11-\mathrm{kg}$ rice rat. Likewise, the data in TABLE 1 show a similar trend but lack of a linear relationship in animal weight vs catch.

\section{DISCUSSION AND CONCLUSION}

No preference for either birds or mammals as a class was found for $C$. furens and C. hollensis in these studies. Hair \& Turner (1968), working at Virginia Beach, Virginia, using animal-baited traps, collected C. furens from tame and wild rabbit, guinea pig, white rat, chicken and Mallard Duck but failed to capture any $C$. hollensis. Both species were, however, collected from man in an adjacent area. They concluded that $C$. furens was 
probably a general feeder and C. hollensis preferred man but that too little was known about these and most Culicoides species to place them into broad categories of ornithophilic or mammalophilic. Our data from field experiments support the conclusion that both $C$. furens and $C$. hollensis are general feeders. In addition, we observed females of both species feeding on the belly and ankles of a horse, beneath the feathers of birds and within the ears of domestic rabbits.

In our experiments, generally more C. furens and $C$. hollensis were trapped with the larger animals than with the small ones, regardless of whether the animals were birds or mammals. Humphreys \& Turner (1973), using the "Bennetttraps," found host size but not color important for C. sanguisuga (Coquillett) and C. guttipennis (Coquillett). Tanner \& Turner (1974), using large and small goats, rabbits and turkeys in the "Turnertraps" placed at different elevations in a Virginia forest, concluded that host size and availability may be more important than type in the host preference of some Culicoides species. Our studies on $C$. furens and $C$. hollensis support their conclusion. Animals of larger size would be expected to exhale greater quantities of carbon dioxide, which is a known attractant for Culicoides (Nelson 1965) and most other hematophagous arthropods. Onyiah (1971) found a significant reduction in Culicoides landing on him when carbon dioxide was extracted from his exhalent breath. The greater attraction of $C$. furens and $C$. hollensis to chickens than to rabbits, which were of similar weights (TABLE 1), could possibly be explained by the greater carbon dioxide production or body heat from the highertemperature avian host. However, the difference in host silhouette and quality and quantity of unidentified host odors or convection currents may be more important.

There was no evidence (TABLE 2) that the Culicoides preferred the wild animals to the domestic ones when the differences in host size were considered. This suggests an overall lack of host specificity for these Culicoides and opportunism in obtaining a blood meal from available hosts. The number of blood meals that either species of $\mathrm{Cu}$ licoides is capable of taking in nature has not been determined, so the significance of a wide host range on disease transmission is not known.

The lack of correlation among trap catches would seem to indicate that the host-seeking population (animal-baited trap catches) was different from the recently emerged population (emergence trap catches) or an unknown segment of the population (sticky cylinder trap catches). However, the strong attractancy of the 16 animal-baited traps may have influenced the catch of the 4 sticky cylinder traps. Bidlingmayer (1961) often found little correlation of $C$. furens biting activity and overall flight activity (measured by truck-trap collections).

The large catch of $C$. furens in the row adjacent to the woods was not expected, since the major breeding areas were towards the north and east (Kline \& Axtell 1977). Resting sites of this species have been investigated and wooded sites appeared to be preferred to more open areas (Bidlingmayer 1961). Castle (1965) presented evidence that another salt marsh species, C. barbosai Wirth \& Blanton, selects its landing or resting sites in the shadowy areas of tree trunks, branches and leaves. C. hollensis may prefer different resting sites than C. furens, but a thorough investigation of the behavior is needed.

The relatively low number of antennal sensory pits in female C. furens (Chu-Wang et al. 1975) and C. hollensis (Axtell, unpubl.) suggests that these species are mammalophilic (Jamnback 1965). However, in our experiments these species were attracted to both avian and mammalian hosts. Our data indicate that host size and availability are the major factors in host choice rather than the class of the host. Therefore, the number of antennal sensory pits is not necessarily an indicator of whether a species is mammalophilic or ornithophilic.

\section{LITERATURE CITED}

Battle, F. V. \& E. C. Turner, Jr. 1971. A systematic review of the genus Culicoides (Diptera: Ceratopogonidae) of Virginia. Insects of Virginia. 3, Res. Div. Bull. No. 44, Va. Polytech. Inst. \& State Univ., Blacksburg, Va. 129 p.

Bennett, G. F. 1960. On some ornithophilic bloodsucking Diptera in Algonquin Park, Ont., Canada. Can. J. Zool. 38: $377-89$.

Bidlingmayer, W. L. 1961. Field activity studies of adult $\mathrm{Cu}$ licoides furens. Ann. Entomol. Soc. Am. 54: 149-56.

Castle, T. A. 1965. An assessment of catches made by sticky cylindrical traps of four different colors compared with sticky materials, in an attempt to determine the resting sites of Culicoides barbosai in a mangrove swamp. Report to Ministry of Health, Jamaica. Aug. 1965. 12 p.

Chu-Wang, I-Wu, R. C. Axtell \& D. L. Kline. 1975. Antennal and palpal sensilla of the sand fly Culicoides furens (Poey) (Diptera: Ceratopogonidae). Int. J. Insect Morphol. Embryol. 4: $131-49$.

Dale, W. E. \& R. C. Axtell. 1976. Salt marsh Tabanidae (Diptera): Comparison of abundance and distribution in Spartina and Juncus habitats. J. Med. Entomol. 12: 671-78.

Dukes, J. C., T. D. Edwards \& R. C. Axtell. 1974. Associations of Tabanidae (Diptera) larvae with plant species in salt 
marshes, Carteret County, North Carolina. Environ. Entomol. 3: 280-86.

Fallis, A. M. 1958. Biting midges (Ceratopogonidae) as intermediate hosts for Haemoproteus of ducks. Proc. 10th Int. Congr. Entomol., Montreal (1956) 3: 681.

Fallis, A. M. \& D. M. Wood. 1957. Biting midges (Diptera: Ceratopogonidae) as intermediate hosts for Haemoproteus of ducks. Can. J. Zool. 35: 425-35.

Gillies, M. T. 1972. Some aspects of mosquito behavior in relation to the transmission of parasites. Zool. J. Linn. Soc. Suppl. I. 51: 69-81.

Hair, J. A. \& E. C. Turner, Jr. 1968. Preliminary host preference studies on Virginia Culicoides (Diptera: Ceratopogonidae). Mosq. News 28: 103-07.

Humphreys, J. G. \& E. C. Turner, Jr. 1973. Blood-feeding activity of female Culicoides (Diptera: Ceratopogonidae). J. Med. Entomol. 10: 79-83.

Jamnback, H. A. 1965. The Culicoides of New York State (Diptera: Ceratopogonidae). N.Y. State Mus. Sci. Serv. Bull. 399. $154 \mathrm{p}$.

Jones, R. H. 1959. Culicoides breeding in human sewage sites of dwellings in Texas. Mosq. News 19: 164-67.

Kettle, D. S. 1977. Biology and bionomics of blood sucking Ceratopogonids. Annu. Rev. Entomol. 22: 33-51.
Kline, D. L. \& R. C. Axtell. 1976. Salt marsh Culicoides (Diptera: Ceratopogonidae): Species, seasonal abundance and comparisons of trapping methods. Mosq. News 36: 1-10.

1977. Distribution of Culicoides hollensis, C. furens and C. bermudensis in relation to plant cover in a North Carolina salt marsh (Diptera: Ceratopogonidae). J. Med. Entomol. 13: 545-52.

Linley, J. R. 1976. Biting midges of mangrove swamps and salt marshes (Diptera: Ceratopogonidae). p. 335-76. In: Cheng, L., ed., Marine insects. American Elsevier, New York. 581 p.

Nelson, R. L. 1965. Carbon dioxide as an attractant for Culicoides. J. Med. Entomol. 2: 56-57.

Onyiah, J. A. 1971. Studies on the biology and ecology of ceratopogonid midges in southern England. Ph.D. Thesis, Univ. of London, England. 163 p.

Tanner, G. D. \& E. C. Turner, Jr. 1974. Vertical activities and host preference of several Culicoides species in a southwestern Virginia forest. Mosq. News 34: 66-70.

Turner, E. C., Jr. 1972. An animal-baited trap for the collection of Culicoides spp. (Diptera: Ceratopogonidae). Mosq. News 32: 527-30. 